\title{
Games and Family Resemblances
}

Consider for example the proceedings that we call "games". I mean board-games, card-games, ball-games, Olympic games, and so on. What is common to them all? Don't say: "There must be something common, or they would not be called 'games'"-- but look and see whether there is anything common to all.-- For if you look at them you will not see something that is common to all, but similarities, relationships, and a whole series of them at that. To repeat: don't think, but look!-- Look for example at board-games, with their multifarious relationships. Now pass to card-games; here you find many correspondences with the first group, but many common features drop out, and others appear. When we pass next to ball games, much that is common is retained, but much is lost.-- Are they all 'amusing'? Compare chess with noughts and crosses. Or is there always winning and losing, or competition between players? think of patience. In ball games there is winning and losing; but when a child throws his ball at the wall and catches it again, this feature has disappeared. Look at the parts played by skill and luck; and at the difference between skill in chess and skill in tennis. Think now of games like ring-a-round-a roses; here is the element of amusement, but how many other characteristic features have disappeared!...

I can think of no better expression to characterize these similarities than "family resemblances";... And I shall say: 'games' form a family.'

Ludwig Wittgenstein, 1953

Even at the ordinary-language level, it is strange to say that all games "have something in common," namely, being games. For some games involve winning and losing, others ("Ring a Ring o'Roses") do not; some games are played for the amusement of the players, others (gladatorial games) are not; some games have more than one player, others do not; and so on. In the same way, when we examine closely all the cases in which we would say that someone has "referred to" something...., we do not find any one relation between the word and the thing referred to. ${ }^{2}$

Hilary Putnam, 1988

The doctrine of family resemblances is tied in a peculiar way to the particular example of games. For although the doctrine has become part of the arsenal of analytic philosophy, on the occasions when philosophers feel a need to support it, the 
example of games is what is supposed to clinch the matter. No one gives Wittgenstein's second example, numbers, probably because it is so unpersuasive. Other examples that philosophers sometimes proffer, for instance, "party," "spot," "train," seem easy enough to define and too slight to matter. More weighty and interesting examples, for instance, "religion," "justice," "reference," are controversial, for there are theories purporting to explain what all just acts or societies, say, have in common; and even if we are unsatisfied with such theories, there remains a real possibility that we may find the true account if we look further. Hence philosophically interesting examples will persuade only if we have already accepted the doctrine of family resemblances on other grounds. As a matter of historical fact, the argument for the doctrine has gone:

The word "game" cannot be defined by a common feature of games, for obviously there is none. We call something a "game" because of its relationship with several things we have called games; we extend our concept along these various resemblances "as in spinning a thread we twist fibre on fibre, " with no fibre running through its whole length. ${ }^{3}$ This is what explains our concept "game"and, probably, a host of other philosophically interesting terms, e.g., "number," "reference," "religion," and so on.

A good way to cast serious doubt on the doctrine, consequently, is to say what is common to games. After all, if the doctrine fails for its most impressive and persuasive example, why believe it? Wittgenstein would owe us new arguments, at the least. That is what I propose to do in this paper.

Wittgenstein's injunction, "Don't think, but look!" is an invitation to miss the forest for the trees. Of course, if you look at games without thinking "you will not see something common 
to them all, but similarities, relationships, and a whole series of them at that." Let's disobey the fatal injunction, and look and think both. A promising place to seek the essence of games is within the class of rule-defined activities, that is, activities it would be impossible to perform without following rules. ${ }^{4}$ So, for example, we could eat, run, and fight without following rules, but we couldn't play chess, bridge, or basketball. Even if monkeys pushed about chess pieces in a way that duplicated a chess game, they would not be playing chess unless they were following the rules of chess.

Of course, there are rule-defined activities that aren't games. Speaking a language, for example (pace Wittgenstein). What makes a rule-defined activity a game? I propose the following theory: A game is a rule-defined activity involving a state which counts as performing the activity successfully because it is so defined by an arbitrary rule, an activity typically performed for the recreation of participants or spectators, or to sharpen skills. This is what all and only games share in virtue of which they are games; also, I believe this account pretty well captures our ordinary concept of games. To put the matter roughly, games are rule-defined play, where success is created by an arbitrary rule..$^{5}$

Chess, to take an obvious example, is a rule-defined activity involving a state (checkmate) that counts as success because it is so defined by a rule, and chess is typically played for the recreation of participants or spectators or to sharpen 
skills. Notice that checkmate isn't success because we strive for it; rather, we strive for checkmate because, according to the rules, it is success. Games have the feature that the success state is in this way internal to the rules. The immediate object of a game is to accomplish the state the rules define as success because it is so defined. Note too that you can play chess but not succeed, as when you play but fail to checkmate. To win a game you must play successfully a game that can be played without succeeding

The example of chess also illustrates the way in which the rule that defines playing a game successfully is arbitrary. We often ask two questions when learning to play a game: "How do I play?" and "What counts as winning?" These questions are different. Knowing how to move the chess pieces according to the rules isn't knowing what counts as winning; indeed, the set of rules that tell me how to move the pieces is compatible with an indefinite number of definitions of winning (e.g., checkmate, taking all your opponents pieces except his king, queening three pawns, etc.) These rules do not determine the success state. Hence the rule defining success is an arbitrary addition in that we could have adopted, consistent with all the other rules, a different definition of success.

Consider the child throwing a ball against a wall and catching it again. Where this activity is a game, the child is following a rule like: "Throw the ball against the wall and catch it, where success is catching the ball you've thrown against the 
wall." 6 A feature of many children's games is that the activity which is the playing of the game is also what is defined by the rule as succeeding. As the activity is usually easy so is performing it successfully, one of the reasons such games provide so much pleasure for children and so little for adults. The rule for Ring around $O^{\prime}$ Roses is: "You and your colleagues hold hands and run in a circle chanting 'Ring a round $O$ ' Roses.... All fall down'; and all fall down roughly when you sing "All fall down', which is succeeding." Where the very activity that constitutes the game is defined as succeeding, there is success but no winning. Note, however, that in each case we could have adopted different definitions of success consistent with the remaining rules, e.g., "Success is catching the ball twenty times in a row" in the first case, and "Success is being the first (or second, or last) player to reach the ground" in the second.

This theory of games explains our ambivalence toward calling sports like boxing "games." Imagine the announcer at a prizefight shouting: "He's up, he's down, he's up again! What a terrific game this is, folks!" Yet boxing is included among the olympic games. Our ambivalence isn't simply because boxing is violent. We have no trouble calling football, rugby, and lacrosse games. Our definition, recall, requires that a game involves a state which counts as success because it is so defined by a rule. Fighting, of course, isn't rule defined. And knocking out your opponent in a brawl is success because that is the goal of a brawl, not because a rule says so. Plainly we made brawling into a sport by 
crafting the rules of boxing to count as success pretty much what is success in a brawl, rules or no. When we view boxing as a game, we must think that a knockout counts as winning because the rule says so. A knockout would be losing if the rule was different. But we also recognize that the rule defines a knockout as winning the fight because it is winning the fight. Consequently we are ambivalent as to whether the success state counts as success because it is so defined by a rule. ${ }^{7}$

Our theory captures the point of the jibe: "Philosophy is just a game." The point is that what counts as success in philosophy has no independent validity or value; it counts as succeeding solely because an arbitrary rule says so. If the rule had been different, something else would count as success. And, according to the jibe, philosophers go for the success state simply because they know it is so defined, not because they are interested in any extrinsic value, for example, truth.

Perhaps the theory sheds some light on the point of Wittgenstein's treatment of language as a collection of "language games." The Augustinian account of language acquisition assumes that human creatures have the natural ability to think about things, that is, to mentally represent objects in the world, plus the ability to transfer the contents of thoughts to words. A language, on this view, is essentially a system of sounds with derived intentionality, used to communicate information about how the world stands. ${ }^{8}$ As Wittgenstein observes: "Augustine describes the learning of a human language as if... the child 
could already think, only not yet speak." 9 If language is made of games, however, what counts as success in playing a language game has no independent or external value or validity; succeeding is wholly internal to the game, which is what defines success. Consequently there is no natural intentionality we transfer to words, the ability to think about things, that determines linguistic success, the ability to talk about things. Augustine is mistaken. The meanings of words can be determined only by their use in a language game. And rules have no derived intentionality to determine how games are played: the meaning of a rule is determined by how it is applied, not the reverse. At bottom, then, intentionality is determined wholly by practices, what we actually say and do. If language is made of games then intentionality is determined by behaviour, a consequence from which Wittgenstein's most striking conclusions flow, for example, that there can be no private language.

What of objections and counter-examples? Consider board games like Monopoly and Gettysburg, which try to craft success in the game so as to mirror winning in a pre-existing competition. If the theory is true, shouldn't we feel at least some of the ambivalence about counting these as games that we feel about boxing? Yet we don't. We might call such pastimes "Representational games": each game is fundamentally an uninterpreted system--bits of wood, coloured squares, and so on-to which a level of representational content is added. But the game could be played uninterpreted. (Consider how we might 
interpret backgammon in various ways.) At this fundamental level of description, winning is wholly rule created: a certain arrangement of bits of wood is winning because the rules say it is. There is no pre-existing competition with bits of wood to which the rules are crafted. Hence representational games are clearly games. But in boxing, there is a pre-existing competition that proceeds at the fundamental level of the game, to which the rules are crafted: competitors are banging away at each other in both cases. Hence our ambivalence.

What about passing the time by trying to solve arithmetical problems and puzzles? This isn't a game, but doesn't it satisfy the definition? Necessarily, solving a problem or a puzzle just is getting the right answer; therefore the arithmetical rules that determine the right answers define what counts as performing the activity successfully. Remember, however, that the rule that defines playing a game successfully is an arbitrary addition, undetermined by the other rules. What counts as playing a game successfully is, in a certain sense, made up out of thin air. But we could not, consistent with the remaining rules, have adopted different right answers to the arithmetical problems, declaring these to be the solutions. For instance, we could not coherently define 5 as the sum of 2+2, while leaving the remaining rules unchanged. If a rule defines the right answer to a mathematical problem, it is not an arbitrary rule. Hence solving arithmetical puzzles for pleasure is not a game. We could, of course, adopt such a rule, e.g., "Success is solving five problems on the first 
try in five minutes," in which case we would be playing a game. ${ }^{10}$ What about reading for pleasure? I follow various rules when I do, and these determine what it is to succeed at reading. Yet reading certainly isn't a game. Here it is helpful to distinguish succeeding at performing an activity, that is, managing to perform it simpliciter, from performing the activity successfully. Consider, for example, the difference between a child succeeding at playing chess, that is, playing chess, and her playing chess successfully, that is, winning. But note too that there are cases where the distinction fails to apply: how does walking successfully differ from succeeding at walking, that is, simply walking? The trouble is that talk of "walking successfully" has been given no definite sense; we don't know what walking "successfully" would be. By contrast, talk of playing games successfully has a clear and robust sense, precisely because each game must involve a state explicitly defined by a rule as playing the game successfully. Even in the special case where the activity that counts as playing the game is what is defined by the rule as playing the game successfully, talk of playing the game successfully has a definite sense. (I have often played Ring Around O' Roses, always successfully.) This helps sort out the alleged counter-instance. Plainly the fact that rules determine what it is to perform an activity simpliciter hardly entails that a rule explicitly defines some state as performing that activity successfully. ${ }^{11}$ For instance, the rules I follow when I read determine what it is to read; but 
talk of "reading successfully" has no more sense than "walking successfully." We don't know what reading "successfully" would be. Hence there is, in fact, no state explicitly defined by a rule as reading successfully. Consequently reading for pleasure isn't a game. Of course, we could adopt such a rule (e.g., "Reading successfully is reading aloud at the rate of 100 words a minute with no mistakes"), in which case we would be playing a game.

Why isn't waltzing a game by our definition? To waltz successfully, it is, of course, necessary to waltz. ${ }^{12}$ But that isn't sufficient. Successful waltzing is waltzing with grace, ease, and beauty. And I submit it is just obvious that beautiful waltzing isn't successful because a rule says it is. The dance is a kind of raw material which is used as a medium to realize aesthetic features, in much the way that clay is sculpted to manifest such properties. It is because we value grace and beauty that we create various mediums for their realization. Beauty is success in waltzing because we strive for beauty; we do not strive for beauty because it is defined as success by a rule. (Contrast a straight line of markers in Bingo.) of course, we could adopt such a rule, in which case waltzing would be a game, as in (heaven forbid!) a waltzing contest.

Wittgenstein writes:

But if someone wished to say: "There is something common to all these constructions--namely the disjunction of all their common properties"-- I should reply: Now you are only playing with words. You might as well say: "Something runs through the whole thread-- namely the continuous overlapping of those fibres". ${ }^{3}$ 
But a game, on our account, is typically played for the recreation of participants or spectators or to sharpen skills. Isn't this the sort of disjunctive definition Wittgenstein explicitly rejects? Well, no. First, all games must share the feature of being rule-defined activities involving a state that counts as performing the activity successfully because an arbitrary rule so defines it. Plainly Wittgenstein has in mind a more radical disjunction, where there is no important commonality and games share only the disjunction of different properties. Second, the disjuncts themselves have something in common, namely, they reflect the fact that success in games is created by an arbitrary rule. We do not typically play a game because we consider its success state intrinsically valuable, nor do we play it because its success state has pre-existing causal connections to other states we value. We create a rule-defined success state and pursue it, not because it has intrinsic value or pre-existing instrumental value, but because we value the pursuit.

Then why not omit the disjunctive condition from the definition? If we lived in a world where legal suits were settled by chess, believing that God would allow only the innocent party to checkmate, and this was the only venue for chess, we would not consider chess a game nor would we consider such endeavours play. ${ }^{14}$ In fact, games are not essentially games, a feature our theory preserves.

To conclude: the doctrine of family resemblances remains alive and influential in analytic philosophy, as the quotation 
from Hilary Putnam illustrates. I believe the doctrine has had an especially pernicious influence on disciplines closely related to philosophy, for example, philosophical theology, where it has become a kind of othodoxy. ${ }^{15}$ I confess to a congenital prejudice against the various siren voices calling us to abandon the traditional philosophical enterprise. I hear them singing sweetly beyond the breakers: "Mariner, why seek the nature of numbers, intentionality, reference, religion, when they have none?" This paper is meant to provide a particularly relevant example of why we should keep looking. Failing better arguments, I propose that we tie ourselves to the mast and sail on. ${ }^{16}$

\section{References}

1. Ludwig Wittgenstein, Philosophical Investigations, Third Edition, G.E.M. Anscombe translator, (Basil Blackwell, 1958), entries 66 and 67. Emphasis in the original.

2. Hilary Putnam, Representation and Reality, (MIT Press, 1988), p. 3. Emphasis in the original.

3. The quotation here is from Wittgenstein, 67. The rest of the sentence containing the quotation closely paraphrases Wittgenstein, 67, except that he is talking about numbers.

4. Rule-defined activities are first discussed in John Rawls, 
"Two Concepts of Rules," Philosophical Review, January, 1955, pp. 3- 32. See especially pp. 22- 29.

5. Jonathan Bennett tells me (in correspondence) that he has defined "game" jokingly as " $\mathrm{x}$ is a game"= "x is not a physical object and $x$ can be played." Professor Bennett, who informs me that he got this "definition" from Ian Hacking twenty-five years ago, uses it to show that there is more to analyzing something than finding a conjunction that is strictly equivalent to it.

6. There are plenty of recreational activities that are merely pleasant pastimes, not games, e.g., playing with a yo-yo. Here there is no state that counts as success because rules define it. Either we simply enjoy performing the activity, e.g, throwing a football back and forth, or we are trying to do tricks and feats (with the yo-yo, say, or balancing a stick on one's nose) which count as success because we are trying to do them. If a child is bouncing a ball against the wall and catching it simply because he finds the activity pleasant, in exactly the way we find throwing a football back and forth pleasant, he is not playing a game.

7. Other states also count as success in boxing, for instance, hitting your opponent far more often than he hits you in each round. But exactly the same point pertains. The rule counts this as winning the fight because it is winning the fight. Note that 
the rule which defines success may be disjunctive, defining success as knocking out your opponent out or hitting him more often than he hits you or...

8. Certainly we do many things with words, but if a language doesn't do this much, it isn't a language.

9. Wittgenstein, 32. Emphasis in the original. Also, see 25. "It is sometimes said that animals do not talk because they lack the mental capacity. And this means: "they do not think, and that is why they do not talk"...

10. In general, rule-defined puzzles and problems aren't games, precisely because success at puzzle solving must be getting the right answer and what counts as a right answer to a puzzle isn't arbitrary; we couldn't have adopted different right answers but held constant the other rules that define the puzzle. Hence, while chess is a game--we could have defined a state other than checkmate as winning, consistent with the other rules-- solving chess problems (e.g., "How can white force mate from this position in two moves?") is not. When we practice logical derivations to sharpen our skills, we are solving logic problems, not playing a game. But couldn't we introduce a game involving the sentential calculus, axioms, transformation rules, and a list of theorems; and define winning as deriving a theorem from the axioms by the rules? And wouldn't that be a game? It would. But 
notice that, in crafting this game, we could also have defined winning as deriving a theorem from the axioms in an even number of lines, or in less than five minutes, or before the other players do, or.... Indeed, we could have defined winning as doing an indefinite number of transformations on the axioms while avoiding all the theorems. To treat a logical calculus as a game, we must view the success state as arbitrary.

11. This is so even if success is defined by the rules as managing to perform the activity, as in Ring around $O^{\prime}$ Roses.

12. Of course, there is the question of whether waltzing is really rule-defined--a trained bear might waltz, but is she following a rule? Let's err on the side of the objection and set this aside.

13. Wittgenstein, 67 .

14. Of course, we would probably remark that chess is like a game.

15. See this author, "A Theory of Religion" in Religious Studies, 27, pp. $337-351$.

16. My thanks to Judith Crane and Norton Nelkin for helpful discussions and comments. 
